\title{
National survey of the oral health of 5-year-old children in the United Arab Emirates
}

M.A.I. El-Nadeef, H. Hassab² and E. Al-Hosani'

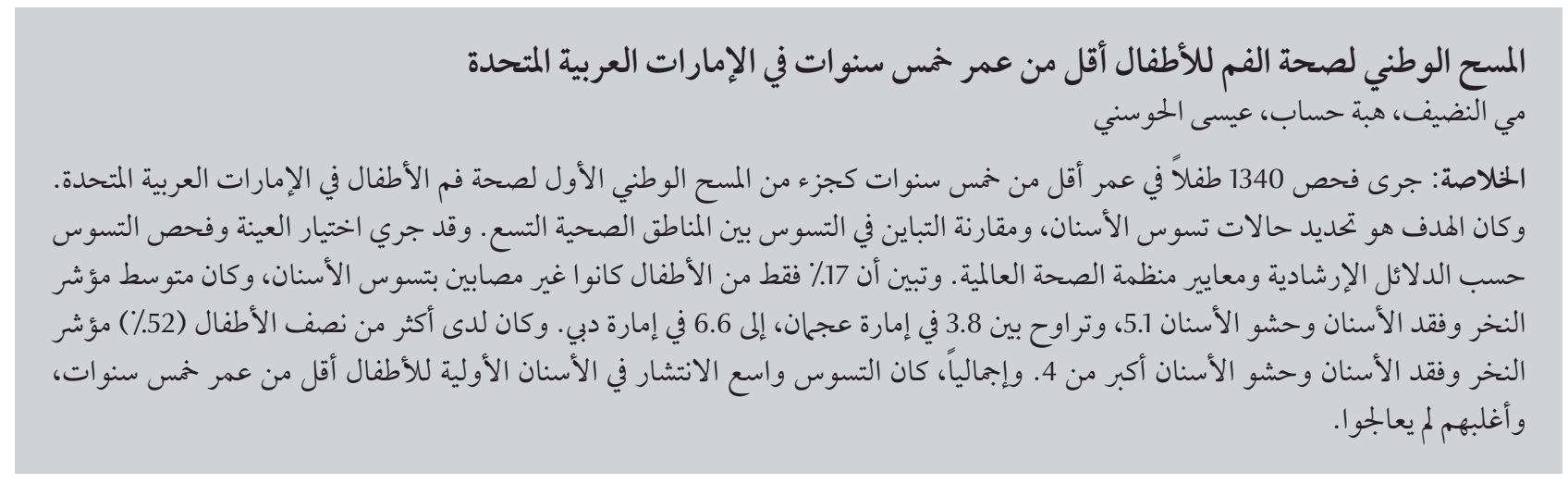

ABSTRACT A total of 1340 5-year-old children were examined as part of the first national survey of the oral health of children in the United Arab Emirates. The objective was to determine dental caries status and compare variations in caries experience in all 9 medical districts. Sampling and examination for caries was done following World Health Organization guidelines and criteria. Only 17\% of the children were caries-free. The mean decayed/missing/filled teeth (dmft) index was 5.1, ranging from 3.8 in Ajman to 6.6 in Dubai. More than half(52\%) had $>4 \mathrm{dmf}$ teeth. Overall, caries is highly prevalent in the primary dentition of 5-year-old children and mostly untreated.

Enquête nationale sur la santé bucco-dentaire des enfants de cinq ans aux Émirats arabes unis

RÉSUMÉ Une population de 1340 enfants âgés de cinq ans a été examinée dans le cadre de la première enquête nationale sur la santé bucco-dentaire des enfants aux Émirats arabes unis. L'objectif était de constater la situation des caries dentaires et de comparer les différentes expériences en la matière dans la totalité des neuf districts médicaux. L'échantillonnage et l'examen des caries ont été réalisés sur la base des directives et des critères de l'Organisation mondiale de la Santé. Seuls $17 \%$ des enfants ne présentaient pas de caries. L'indice CAO moyen (nombre de dents cariées, absentes ou obturées) était de 5,1, avec des valeurs allant de 3,8 à Ajman à 6,6 à Dubaï. Plus de la moitié (52\%) des enfants avaient un indice CAO supérieur à 4. Dans l'ensemble, la prévalence des caries sur les dents de lait des enfants de cinq ans est élevée ; ces caries sont rarement traitées. 


\section{Introduction}

Over the past 20 years, information on dental caries among children in the United Arab Emirates (UAE) has been collected from pathinder surveys but these did not represent all 7 Emirates. Reports on dental caries experience in the primary dentition were mainly from Abu Dhabi. In 1991 there were 3 reports on caries in the primary dentition of 5-6-year-olds: mean number of decayed, missing or filled primary teeth $(\mathrm{dmft})$ was reported as 5.1 for 5-year-old children in Abu Dhabi city [1]; the second study reported $6.3 \mathrm{dmft}$ for 6-year-olds in 3 cities in the UAE [Unpublished report, K. Cowles, E. Beltran, 1991]; and the third reported an average $\mathrm{dft}$ of 6.8, 4.0, 3.0 and 6.2 for Abu Dhabi, Dubai, Sharjah and Fujairah respectively [Unpublished report, P. Leous, 1991]. In 1998, a mean dmft of 7.7 for was reported 5-year-olds in Abu Dhabi [2]. These reports suggested an increasing trend of dental caries in the primary dentition of children in the UAE.

Primary teeth begin to shed from about the age of 5 years onwards. If children are examined after this age, the record of primary teeth will be incomplete. For countries such as the UAE, where children are mostly attending school at 5 years of age, this is a better age group to survey than 6 years, which is commonly used in surveys in some countries.

Three age groups of children, 5, 12 and 15 years, were covered in the national survey of the oral health of children in the UAE. Recognizing the importance of reliable information on the oral health problems and trends, the Preventive Dentistry Section or the Ministry of Health took the initiative in conducting the first national survey of the oral health of 5-year-old children in the UAE. The findings for the other 2 age groups have been described elsewhere [3].
The objective of this survey was to determine the status of dental caries in the primary dentition of 5-year-old children and to compare variations in caries experience among the 7 Emirates as well as differences according to sex and nationality.

\section{Methods}

Approval for conducting the survey was obtained from the Ministry of Health, Ministry of Education and appropriate authorities in each medical district. Written consent was sought from parents prior to the child's examination. Only children whose parents consented were examined. The dental survey was conducted during 2001/2002.

\section{Sampling}

The sampling methods followed the guidelines for oral health surveys published by the World Health Organization (WHO) [4]. The size of the sample was determined according to the guidelines which state that the smallest cell size should be $\geq 40$. It was decided to sample about 150 children in each of the 9 medical districts to allow for some non-participation. Thus the sample size was 1350 children altogether. As the size of the population within each of the medical districts differs, the proportion of children who were sampled differed accordingly. Therefore, the mean scores for each district had to be weighted appropriately.

Five-year-old children in private and state schools in all medical districts were included. Onlyafewcommunityschools were excluded. Sampling was done in 2 stages: by school within the medical district and by child within schools. Schools were selected using random number tables unless the number of schools in a district was small, in which case all schools were included. Within each school, children were randomly selected with frequency according to the size of the school. This meant that each child within each district had an equal chance of being chosen. No replacement was made for children who were not examined.

\section{Standardization of examiners}

Nine dentist examiners, 1 in each district, examined the children. Training sessions were conducted and each examiner re-examined a $10 \%$ sample of children in order to assess examiner reproducibility; this was expressed as the reliability coefficient for the $\mathrm{dmft}$ index [5]. This was calculated for each examiner.

\section{Examination of children}

The children were examined in a supine position on a flat table. All examinations were carried out under natural and artificial room light, but without a spotlight. No special tooth-cleaning was done before examination. A plane mouth mirror (number 4) and a blunt explorer (0.5 mm diameter tip) were used. The examination was principally visual. The explorer was used for removal of plaque and debris, and as a diagnostic aid for proximal and fissure sites. Diagnosis of dental caries followed WHO criteria and the recording was done on a modified WHO form [4].

\section{Data handling}

The numeric information entered on the recording form was checked for completeness before being entered into a computer file. SPSS, version 7.5, data files were created and data were subjected to checks for completeness. Missing data were recorded as such. We calculated decayed teeth $(\mathrm{dt})$, missing teeth $(\mathrm{mt})$, filled teeth $(\mathrm{ft})$ and $\mathrm{dmft}$ for each child. Descriptive statistics expressed as percentage prevalence of dental caries and mean number of teeth affected by dental caries per mouth (as a measure of caries severity) were calculated according to sex, medical district and nationality. 


\begin{tabular}{|c|c|c|c|c|c|c|c|c|c|c|c|}
\hline \multirow[t]{2}{*}{ Medical district } & \multirow{2}{*}{$\begin{array}{c}\text { Total } \\
\text { No. }\end{array}$} & \multicolumn{2}{|c|}{ Examined } & \multicolumn{2}{|c|}{ Males } & \multicolumn{2}{|c|}{ Females } & \multicolumn{2}{|c|}{ UAE nationals } & \multicolumn{2}{|c|}{$\begin{array}{c}\text { Non- } \\
\text { nationals }\end{array}$} \\
\hline & & No. & $\%$ & No. & $\%$ & No. & $\%$ & No. & $\%$ & No. & $\%$ \\
\hline Abu Dhabi & 6639 & 150 & 2 & 75 & 50 & 75 & 50 & 119 & 79 & 31 & 21 \\
\hline Al Ain & 5432 & 149 & 3 & 79 & 53 & 70 & 47 & 123 & 83 & 26 & 17 \\
\hline Western Region & 444 & 151 & 34 & 77 & 51 & 74 & 49 & 85 & 56 & 66 & 44 \\
\hline Dubai & 1339 & 151 & 11 & 65 & 43 & 86 & 57 & 151 & 100 & 0 & 0 \\
\hline Sharjah & 2014 & 151 & 7 & 69 & 46 & 82 & 54 & 151 & 100 & 0 & 0 \\
\hline Ajman & 1713 & 161 & 9 & 86 & 53 & 75 & 47 & 110 & 68 & 51 & 32 \\
\hline Umm Al Quwain & 488 & 150 & 31 & 73 & 49 & 77 & 51 & 137 & 91 & 13 & 9 \\
\hline Ras Al Khaima & 1640 & 150 & 9 & 79 & 53 & 71 & 47 & 149 & 99 & 1 & 0 \\
\hline Fujairah & 1233 & 127 & 10 & 75 & 59 & 5 & 41 & 127 & 100 & 0 & 0 \\
\hline Total & 20942 & 1340 & 6 & 678 & 51 & 662 & 49 & 1152 & 86 & 188 & 14 \\
\hline
\end{tabular}

\section{Results}

The total number of children aged 5 years at school in the UAE was 20942. The total number of children examined was 1382 (Table 1), representing 6\% of 5-year-olds in school. There was a high response rate, $96.7 \%$ of those selected were examined; the number of boys and girls was approximately equal. Non-nationals constituted $14 \%$ of the number of children examined (Table 1 ), and the most common countries of origin were Egypt, Palestine, Syrian Arab Republic and Jordan.

Examiner reproducibility was measured by the reliability coefficient calculated for re-examination of $10 \%$ of children. The data obtained indicated high reliability (average 0.97).

The proportion of 5-year-olds who had caries experience in the primary dentition was $83 \%$ overall; this varyied from $71 \%$ in Ajman to $93 \%$ in the Western Region (Table 2). A high proportion ( $52 \%$ overall) had $>4$ teeth with decay experience; $10 \%$ had had teeth extracted due to caries and 13\% had had teeth filled. Most of the teeth with decay, however, were unfilled (Table 3).

The mean $\mathrm{dmft}$ was 5.1, varying from $3.8 \mathrm{dmft}$ in Ajman to $6.6 \mathrm{dmft}$ in Dubai
(Table 3). The filled component of the $\mathrm{dmft}$ values was only $0.3 \mathrm{ft}$ overall, highest in Abu Dhabi medical district (0.6 $\mathrm{dmft}$ ). Caries experience was similar in boys ( $5.1 \mathrm{dmft})$ and girls $(4.9 \mathrm{dmft})$ both overall and within each medical district. There was also little difference between the sexes in the $\mathrm{mt}$ and $\mathrm{ft}$ components. Likewise, there was little difference in $\mathrm{dmft}$ values between nationals and nonnationals, although non-nationals in Ras Al Khaima medical district had very high caries experience $(10.0 \mathrm{dmft})$ with no teeth extracted or filled. For UAE nationals, caries experience was highest in
Dubai ( $6.6 \mathrm{dmft})$ and Western Region (6.5 dmft).

In our sample of 5-year-olds, the first permanent molars had erupted in $18 \%$ of the children and $11 \%$ of these already had dental caries experience.

\section{Discussion}

In our study, the mean dmft was 5.1, which varied from $3.8 \mathrm{dmft}$ in Ajman to $6.6 \mathrm{dmft}$ in Dubai; there was no significant difference between boys and girls in $\mathrm{dmft}$ values. Although previous studies

\begin{tabular}{|c|c|c|c|}
\hline $\begin{array}{l}\text { Table } 2 \text { Caries sta } \\
\text { Arab Emirates }\end{array}$ & ildren in & nedical dis & the Unitec \\
\hline Medical district & & tatus of chil & \\
\hline & $\begin{array}{c}\text { Free } \\
(\mathbf{d m f t} 0)\end{array}$ & $\begin{array}{l}\text { Moderate } \\
\text { (dmft 1-4) }\end{array}$ & $\begin{array}{c}\text { High } \\
(\mathrm{dmft}>4)\end{array}$ \\
\hline Abu Dhabi & 18 & 36 & 46 \\
\hline Al Ain & 22 & 39 & 39 \\
\hline Western Region & 7 & 28 & 65 \\
\hline Dubai & 11 & 27 & 62 \\
\hline Sharjah & 15 & 27 & 58 \\
\hline Ajman & 29 & 39 & 32 \\
\hline Um Al Quwain & 21 & 29 & 50 \\
\hline Ras Al Khaimah & 19 & 25 & 56 \\
\hline Fujairah & 13 & 30 & 57 \\
\hline
\end{tabular}

$d m f t=$ delayed, missing and filled teeth . 


\begin{tabular}{lcccc}
\hline \multicolumn{5}{l}{ Table 3 Distribution of 5-year-old children in each medical district in the United } \\
Arab Emirates with experience of decayed, missing or filled teeth \\
\hline Medical district & $\mathbf{d t}$ & $\mathbf{m t}$ & $\mathrm{ft}$ & Mean dmft \\
Abu Dhabi & 77 & 9 & 22 & 4.9 \\
Al Ain & 78 & 9 & 9 & 4.4 \\
Western Region & 91 & 0 & 19 & 6.4 \\
Dubai & 88 & 11 & 9 & 6.6 \\
Sharjah & 83 & 23 & 7 & 6.1 \\
Ajman & 68 & 14 & 14 & 3.8 \\
Um Al Quwain & 77 & 5 & 19 & 5.3 \\
Ras Al Khaimah & 80 & 13 & 5 & 6.2 \\
Fujairah & 86 & 7 & 9 & 6.1 \\
\hline
\end{tabular}

$d t=$ decayed teet $; \quad m t=$ missing teet $;$ f $t=$ filled teet .

in the UAE were limited in size (sample size $<500$ ) and geographical coverage, it appears that that caries experience in the primary dentition has been high (>5 dmft) for at least 12 years $[1,2, \mathrm{~K}$. Cowles, E. Beltran, unpublished report, 1991]. In other countries in the region, caries experience is also reported to be high. For example, over the same time period, in Kuwait, values of $6.2 \mathrm{dmft}$ and $4.6 \mathrm{dft}$ in 6-year-olds have been reported $[6,7]$; in Saudi Arabia, a value of 7.3 $\mathrm{dmft}$ in 6-7 year olds [8]; in Bahrain,a value of $7.1 \mathrm{dmft}$ in 5-year-olds [WHO Data Bank]; in Oman, a value of 4.6 $\mathrm{dft}$ in 6-year-olds has bee reported [9] and in Iraq, values of 4.8 in 6-year-olds and $2.3 \mathrm{dmft}$ in 7 -year-olds [10]. These values are much higher than those now recorded (of under $2 \mathrm{dmft}$ ) in Northern Europe [11].

The value of $\mathrm{dmft}$ has been reported to range from 0.94 to 2.55 in the United Kingdom [12]. However, dmft values were just as low in Sudan, 1.68 [13] and Tunisia, 0.1 [14] and in the Libyan Arab Jamahiriya dft was 1.1 and 2.7 in children of comparable age [15] (Table 4).

In spite of remarkable progress in the provision of dental health services in the UAE, dental caries remains a considerable public health problem in young children. To avoid a further increase in the prevalence of decay, we recommend treatment be given in parallel with intensive promotion of oral health and disease prevention, targeting young children and expectant mothers.

The current mother and child preventive programme should be encouraged and reinforced in all maternity health centres. There is a large body of evidence that supports the importance of the implementation of caries preventive and management measures as early as possible before birth as well as during postnatal care [13]. Fluoride use and dietary counselling for mothers during pregnancy and after birth for their young children have been shown to be effective in preventing and reducing the risk of dental caries in infants and preschool children $[11,16]$.

\section{Acknowledgement}

This study was conducted by the Preventive Dentistry Section of the Dental Department, Ministry of Health, United Arab Emirates and is a result of a team effort of a large group of people. Our special thanks go to the project supervisors and the staff members of the survey teams.

\begin{tabular}{lccccc}
\hline \multicolumn{7}{l}{ Table 4 Caries experience in primary dentition for children in the Middle East } & & & \\
\hline Survey year & $\begin{array}{c}\text { Age } \\
\text { (years) }\end{array}$ & Country & No. & Mean dmft & Reference \\
1993 & 6 & Kuwait & - & 6.2 & {$[6]$} \\
2001 & 6 & Kuwait & - & $4.6 \mathrm{dft}$ & {$[7]$} \\
2002 & $6-7$ & Saudi Arabia (Riyadh) & 602 & 7.3 & {$[8]$} \\
1994 & 6 & Oman & - & $4.6 \mathrm{dft}$ & {$[8]$} \\
1989 & $6-7$ & Iraq & - & 4.8 & {$[10]$} \\
1995 & $6-7$ & Iraq & 1047 & 2.3 & {$[10]$} \\
1990 & $4-5$ & Sudan & 275 & 1.68 & {$[13]$} \\
1994 & 6 & Tunisia & 600 & 0.1 & {$[14]$} \\
1994 & 6 & Libyan Arab Jamahiriya, rural & - & $1.1 \mathrm{SVD} \mathrm{dft}$ & {$[15]$} \\
1994 & 6 & Libyan Arab Jamahiriya, Benghazi & - & $2.7 \mathrm{dft}$ & {$[15]$} \\
\hline
\end{tabular}

$d m f t=$ delayed, missing and filled teeth; $d f t=$ delayed and filled teeth. 


\section{References}

1. Al-Mughery AS, Attwood D, Blinkhorn AS. Dental health of 5-year-old children in Abu Dhabi, United Arab Emirates. Community dentistry and oral epidemiology, 1991, 19:308-9.

2. Al-Hosani E, Rugg-Gunn AJ. Combination of low parental educational attainment and high parental income related to high caries experience in pre-school children in Abu Dhabi. Community dentistry and oral epidemiology, 1998, 26:31-6.

3. El-Nadeef $M$ et al. National survey of the oral health of 12- and 15 -year old schoolchildren in the United Arab Emirates. Eastern Mediterranean health journal, 2007, 15(4):993-1004.

4. Oral health surveys: basic methods, 4th ed. Geneva, World Health Organization, 1997.

5. Rugg-Gunn AJ, Holloway PJ. Methods of reliability of caries prevalence and incremental data. Community dentistry and oral epidemiology, 1974, 2:287-94.

6. Vigild $\mathrm{M}$ et al. Dental caries and dental fluorosis among 4-, 6-, 12- and 15-year-old children in kindergartens and public schools in Kuwait. Community dental health, 1996, 13:47-50.

7. Al-Mutawa SA et al. Dental caries experience of Kuwaiti schoolchildren. Community dental health, 2006, 23:31-6.

8. Al-Wazzan KA. Dental caries prevalence in 6-7-year-old schoolchildren in Riyadh region: comparative study with the 1987 oral health Survey of Saudi Arabia Phase I. Saudi dental journal, 2004, 16:54-60.
9. Al-Ismaily M et al. Prevalence of dental caries in Omani 6-yearold children. Community dental health, 1997, 14:171-4.

10. Jamel H et al. Dental caries experience and availability of sugars in Iraqi children before and after the United Nations sanctions. International dental journal, 2004, 54:21-5.

11. Prevention and management of dental decay in the pre-school child. A national clinical guideline. Edinburgh, Scottish Intercollegiate Guidelines Network (SIGN), 2005 (SIGN publication No. 83).

12. Pitts NB, Evans DJ, Nugnet ZJ. The dental caries experience of 5 -year-old children in Great Britain. Surveys coordinated by the British Association for the study of community dentistry in 1999/2000. Community dental health, 2001, 18:49-55.

13. Raadal $M$ et al. The prevalence of caries in groups of children aged 4-5 and 7-8 in Khartown, Sudan. International journal of paediatric dentistry, 1993, 3:9-15.

14. Abid A. Oral health in Tunisia. International dental journal, 2004, 54(Suppl. 1):389-94.

15. Hawew RM et al. Dental caries in children from two Libyan cities with different levels of fluoride in their drinking water. Community dental health, 1996, 13:175-7.

16. Beiruti N. Views on oral health care strategies. Eastern Mediterranean health journal, 2005, 11(1/2):209-16.

\section{Milk fluoridation for the prevention of dental caries}

Around the globe, dental caries is a public health problem and the disease burden is particularly high among underprivileged groups. In several low-income countries, the WHO anticipates that the incidence of dental caries will increase as a result of growing consumption of sugars and inadequate exposure to fluorides.

The good news is that dental caries is preventable through the effective use of fluoride. WHO emphasizes the importance of automatic administration of fluoride as part of public health programmes. Substantial research has provided evidence of the effectiveness of milk fluoridation in the prevention of dental caries. As milk fluoridation mostly targets the child population, such schemes have been established within the context of school health programmes and programmes for healthy diet and nutrition. This publication, Milkfluoridation for the prevention of dental caries, describes the justification of milk fluoridation as an effective public health measure and experiences from community health programmes are highlighted.

Further information about this and other WHO publications can be found at: http:/ / www.who.int/bookorders/ anglais/homel.jsp?sesslan=1 